\title{
Roles of antimicrobial peptides such as defensins in innate and adaptive immunity
}

\author{
J J Oppenheim, A Biragyn, L W Kwak, D Yang
}

Ann Rheum Dis 2003;62(Suppl II):ii 17-ii2 1

A number of antimicrobial peptides such as defensins have multiple functions in host defence. Defensins are produced not only by phagocytic cells and lymphocytes, but also by the epithelial cell lining of the gastrointestinal and genitourinary tracts, the tracheobronchial tree, and keratinocytes. Some are produced constitutively, whereas others are induced by proinflammatory cytokines and exogenous microbial products. Defensins produced by cells in the course of innate host defence serve as signals which initiate, mobilise, and amplify adaptive immune host defences. Administration of defensins with antigens to mice enhances both cellular (Th 1-dependent) and humoral (Th2-dependent) cytokine production and immune responses. Linkage of defensins to weak tumour antigens potentiates their immunoadjuvant effects. Defensins use multiple cellular receptors, which endows them with the capacity to marshall adaptive host defences against microbial invaders.

A nimals live in an environment filled with pathogenic microorganisms. If the epithelial barrier is breached by an injury, pathogens that invade the host are eliminated initially by innate, followed by adaptive, host immune reactions. Innate immunity consists of a range of pre-existing rapidly mobilised host defences including neutrophil and macrophage phagocytic cells, epithelial cells, mast cells, eosinophils, and natural killer cells. ${ }^{12}$ These cells express a wide variety of pattern recognition receptors, such as toll-like receptors (TLRs), C lectin receptors, and scavenger receptors, which are activated by components of microbial pathogens. This results in the release and/or activation of numerous effector molecules and mediators of host defence including the complement cascade, cytokines, chemokines, superoxides, nitric oxides, prostaglandins, acute phase proteins, and antimicrobial peptides. In this paper, we will review the multiple means by which antimicrobial peptides-defensins and cathelicidin in particular-activate not only innate but also adaptive immune responses.

Adaptive immune responses are activated by the following sequence of cellular interactions. Specialised cellular members of the innate immune system function to activate adaptive immune reactions. They consist of pre-existing Langerhans cells of the skin and immature dendritic cells (iDCs), which can phagocytose microbial proteins and process them into small peptide fragments. ${ }^{3}$ As the dendritic cells mature in response to inflammatory stimuli, these small (8-9 amino acid) peptides are exported on to the cell surface together with MHC proteins. ${ }^{3}$ The complex of MHC and antigenic epitopes is presented by these now mature dendritic cells to those T cells in the lymph nodes that express a complementary $\mathrm{T}$ cell receptor for the antigen. Class I MHC-antigen complexes preferentially activate CD8 cytotoxic T cells, whereas class II MHC-antigen complexes activate CD4 helper T cells, which produce immunoenhancing cytokines that promote adaptive
B cell proliferation and antibody production. Other cytokines produced by $\mathrm{T}$ cells in turn activate phagocytic macrophages and neutrophils as well as natural killer cells, resulting in positive feedback augmentation of innate defences.

A wide variety of host proteins have been shown to have antimicrobial activity. Antimicrobial peptides such as defensins are widely distributed in nature and are found not only in vertebrates, but also in invertebrates and even in the plant kingdom. ${ }^{4}$ Antimicrobial peptides are produced by leucocytes and epithelial cells lining the environmental interface of the gastrointestinal and genitourinary tracts, tracheobronchial tree, and skin. They include defensins, cathelicidin, histatins, cathepsin G, azurocidin, chymase, eosinophil derived neurotoxin, high mobility group 1 nuclear proteins, HMGB1, lactoferrin, and many others. ${ }^{4-8}$ This overview will focus on defensins and cathelicidins of mice and men.

Many of the antimicrobial peptides are constitutively present in cells and stored in secretory granules. Others are induced by proinflammatory stimuli. They exhibit large cationic patches on their molecular surface which enables them to depolarise and/or pierce bacterial cell membranes. However, the antibacterial and antifungal activities of defensins, cathelicidins, and selected chemokines are inhibited by physiological salt concentrations and by serum. ${ }^{56}$ Consequently, their microbicidal activities may be exerted largely in phagocytic vacuoles and on the external surface of the skin and mucosa. ${ }^{7}$ Some of the antimicrobial peptides have potent in vitro antiviral activities. Both $\alpha$ defensins and eosinophil derived neurotoxin have been reported to have considerable anti-HIV-1 activity. ${ }^{90}$ In fact, $\alpha$ defensins are said to account for the soluble CD8 antiviral factor secreted by CD8 T lymphocytes from long term nonprogressing HIV-l positive patients.'

\section{STRUCTURE OF DEFENSINS AND CATHELICIDIN}

The defensins can be classified into two subfamilies based on their tertiary structure. They exhibit considerable variation in their amino acid sequences, perhaps based on selective pressures to enable them to contend with a wide variety of microbial agents. The human $\alpha$ defensins, although small (3.5-4 kDa), have three intramolecular cysteine bonds linking cysteines $1-6,2-4$, and $3-5$, whereas the $\beta$ defensins (4-6 kDa) have bonds between cysteines 1-5, 2-4, and 3-6. Consequently, these small molecules have an intricate tertiary structure with a core of three anti-parallel $\beta$ sheet components resembling chemokines. ${ }^{11} 12$

In contrast, cathelicidin (LL37) consists of the linear C terminus of the human CAP-18 molecule, has an $\alpha$-helical structure, and interacts with the formyl peptide receptor-like 1 (FPRL1) G protein coupled receptor rather than with a chemokine receptor. ${ }^{13} 14$

Abbreviations: iDC, immature dendritic cell; IFN, interferon; IL, interleukin; LPS, lipopolysaccharide; MBD, murine $\beta$ defensin; TLR, toll-like receptor; TNF, tumour necrosis factor 
Table 1 Cell sources of human defensins and cathelicidin

\begin{tabular}{|c|c|c|}
\hline Peptide & Constitutive expression & $\begin{array}{l}\text { Induced by proinflammatory cytokines } \\
\text { and endotoxin (LPS) }\end{array}$ \\
\hline$\alpha$ Defensins (HNP1-3) & Neutrophil granules & $\begin{array}{l}\text { Monocytes }^{15} \\
\text { CD8 T lymphocytes (CTL) }\end{array}$ \\
\hline \multirow{3}{*}{$\begin{array}{l}\alpha \text { Defensins (HD5-6) } \\
\beta \text { Defensins (HBDI) }\end{array}$} & Paneth cell granules & \\
\hline & Keratinocytes & Keratinocytes $^{35}$ \\
\hline & Barrier epithelial cells & $\begin{array}{l}\text { Monocytes and dendritic cells } s^{36} \\
\text { Monocytes and dendritic cells } s^{36}\end{array}$ \\
\hline \multirow{2}{*}{$\beta$ Defensins (HBD2-4) } & & Keratinocytes ${ }^{14} 19$ \\
\hline & & $\begin{array}{l}\text { Barrier epithelial cells }{ }^{14} 19 \\
\text { Mast cells } s^{37}\end{array}$ \\
\hline \multirow[t]{5}{*}{ Cathelicidin (LL-37) } & Neutrophil granules & Keratinocyłes $^{13} 15$ \\
\hline & & Barrier epithelial cells $^{13} 15$ \\
\hline & & Monocytes $^{15}$ \\
\hline & & T lymphocytes ${ }^{15}$ \\
\hline & & Mast cells $^{38}$ \\
\hline
\end{tabular}

\section{CELL SOURCES AND INDUCTION OF DEFENSINS AND CATHELICIDIN}

The $\alpha$ defensins, also known as the human neutrophil peptides (HNPl-3), are largely stored in the granules of neutrophils and to a lesser extent in macrophages (table 1). They are constitutively produced by myeloid precursor cells. However, recent reports suggest that their production can be induced by activated CD8 T cells as well. ${ }^{9}{ }^{15}$ In contrast, HD5 and HD6 are stored in the granules of Paneth cells at the base of villi in the gastrointestinal tract. When induced to degranulate, neutrophils and Paneth cells release these $\alpha$ defensins locally. The pathophysiological roles of the various defensins have been difficult to establish because there are too many genes to readily delete. However, knockout mice lacking the matrilysin (metalloproteinase 7) enzyme, which is required to cleave the proforms of Paneth cell derived HD5 and HD6, did have reduced resistance to gastrointestinal pathogens. ${ }^{16}$ As this cleavage is not the only function of matrilysin, this observation is not definitive. There is abundant evidence that $\alpha$ defensin concentrations do become considerably elevated at sites of acute inflammation, ${ }^{17}$ and plasma concentrations are increased in systemic infectious diseases. ${ }^{18}$

There are also many $\beta$ defensins. HBDl is expressed constitutively by keratinocytes and found in the interstices between the cells. HBD2-4 on the other hand are inducible and produced by keratinocytes and epithelial cells in response to proinflammatory stimuli such as interleukin (IL)-1, tumour necrosis factor (TNF), and lipopolysaccharide (LPS). ${ }^{14}{ }^{19}$ Evaluation of the human genome suggests that there may be an additional $25 \beta$ defensins that have not yet been identified..$^{20}$ Despite this apparent redundancy, deletion of the gene for HBDl does delay the capacity of knockout mice to clear haemophillus influenza from the lung ${ }^{21}$ and results in increased colonisation by Staphylococcus in the bladder. ${ }^{22}$ Cathelicidin is both stored in neutrophil granules and is an inducible product of epithelial cells, T cells, and monocytes. Deletion of the murine homologue, CRAMP, reduces resistance of mice to infectious challenge of the skin. ${ }^{23}$

\section{CHEMOTACTIC ACTIVITIES OF DEFENSINS AND CATHELICIDIN}

In addition to their innate antibacterial role, many of these peptides have recently been shown to interact with various receptors on iDCs and lymphocytes, resulting in activation of adaptive immune responses. This conclusion is based on the chemotactic effect of antimicrobial peptides for selected leucocytes. This chemotactic ability of the antimicrobial peptides indicates that they can attract host cells expressing the appropriate receptors along a gradient to their site of origin. ${ }^{24}$ Furthermore, as their chemotactic responses are inhibitable by pertussis toxin, the antimicrobial peptides interact with Goi protein coupled receptors. The receptor has been identified in the case of $\beta$ defensins as CCR6, which is shared by the chemokine MIP3 $\alpha /$ LARC/CCL20. ${ }^{25}$ The $\alpha$ defensins were reported to interact with the $\mathrm{G}$ protein coupled receptor for adrenocorticotrophic hormone a number of years ago, which may account for their capacity to suppress glucocorticoid production. ${ }^{26}$ This suppressive effect would be predicted to further promote the immunoenhancing capabilities of $\alpha$ defensins. Although the chemotactic effects of cathelicidin for neutrophils, monocytes, and T lymphocytes are also pertussis toxin inhibitable, it does not interact with a chemokine receptor, but with FPRL1. ${ }^{13}$

Predictably, human and murine defensins are chemotactic for those cells that express the appropriate receptors (table 2). Although the receptor for $\alpha$ defensins has not been identified as yet, the chemotactic effects of $\alpha$ defensins are inhibitable by pertussis toxin, identifying it as a Goi protein coupled receptor. The $\alpha$ defensins are chemotactic for immature, but not mature, dendritic cells and the subset of naive resting CD4CD45RA and some CD8 T lymphocytes, but not neutrophils or monocytes. ${ }^{27}$ The $\beta$ defensins are selectively chemotactic only for CCR6 expressing cells, including iDCs and resting memory CD4CD45RO as well as some CD8 T lymphocytes. ${ }^{25} \mathrm{HBD} 3$ is also chemotactic for monocytes, which do not express CCR6, suggesting it uses an additional chemotactic receptor. ${ }^{28}$ The defensins do not induce calcium flux. On

Table 2 Chemotactic targets of human defensins and cathelicidin

\begin{tabular}{|c|c|c|c|c|c|c|}
\hline Peptides & Monocytes & Endothelial cells & Neutrophils & Mast cells & T Cells & iDCs \\
\hline$\alpha$ Defensins 1-3 & - & $++^{18}$ & - & ND* & Naive + CD $8^{27}$ & $+{ }^{27}$ \\
\hline$\beta$ Defensins 1-2 & - & ND & - & -30 & Memory + CD8 $8^{25}$ & $+{ }^{27}$ \\
\hline$\beta$ Defensins 3-4 & $++^{28}$ & ND & - & ND & Memory + CD8 ${ }^{25}$ & $+^{25}$ \\
\hline Cathelicidin (LL37) & $++^{13}$ & ND & $+{ }^{13}$ & $t^{31}$ & $++^{13}$ & - \\
\hline
\end{tabular}


Table 3 Activities of human defensins

\begin{tabular}{|c|c|}
\hline Peptide & Innate and adaptive immune effects \\
\hline$\alpha$ Defensins (HNP1-3) & 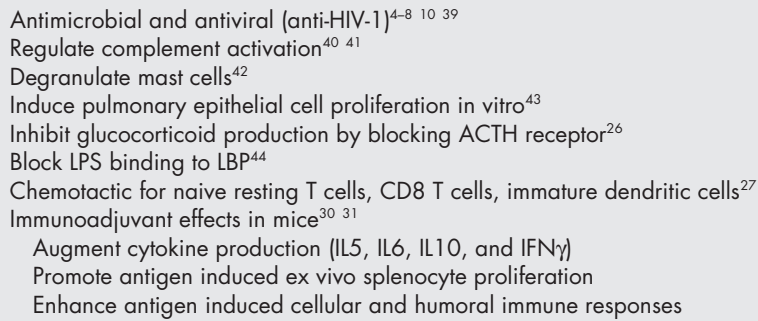 \\
\hline$\beta$ Defensins (HBD1-3) & $\begin{array}{l}\text { Antimicrobial } 14-8 \\
\text { Induce prostaglandin } \mathrm{D}_{2} \text {, production }{ }^{29} \\
\text { Degranulate mast cells }{ }^{29} \\
\text { Chemotactic for CCR6 dendritic cells } s^{25} \\
\text { HBD3 also acts on unknown GPCR on monocytes }{ }^{15} \\
\text { Immunoadjuvant effects in mic }{ }^{32} 33 \\
\text { Enhance tumour antigen induced humoral and cellular immunity } \\
\text { HBD2 induces cytokines and chemokines } \\
\text { HBD2 also activates TLR4 iDCs }\end{array}$ \\
\hline
\end{tabular}

ACTH, Adrenocorticotrophic hormone; GPCR, G protein coupled receptor; iDC, immature dendritic cell; IFN interferon; IL, interleukin; LPB, lipopolysaccharide binding protein; LPS, lipopolysaccharide; TLR, toll-like receptor; TNF, tumour necrosis factor.

the basis of usage of chemokine receptors and the tertiary structural similarities between defensins and chemokines, ${ }^{12}$ the defensins can actually be considered to be "microchemokines" which act on cells of the adaptive immune system.

\section{BIOLOGICAL ACTIVITIES OF DEFENSINS AND CATHELICIDIN}

The $\alpha$ defensins have been reported to have a number of biological activities (table 3 ). They degranulate mast cells resulting in the release of histamine. ${ }^{29}$ Intranasal administration of $\alpha$ defensins along with an antigen enhances the systemic cellular and humoral immune responses to that antigen. ${ }^{30}$ This is associated with enhanced ex vivo production of both Thl and Th2 type cytokines such as ILl, TNF, IL6, IL4, and interferon (IFN) $\gamma$ by splenocytes from such mice. Systemic injections of human $\alpha$ defensins into mice also results in augmentation of both Thl and Th2 immune responses to potent as well as weaker tumour antigens. ${ }^{31}$ Thus human $\alpha$ defensins are active across species in mice and have potent immunoadjuvant effects.

\section{DEFENSINS AUGMENT IMMUNITY TO TUMOUR ANTIGEN}

Although human $\beta$ defensins are inactive in mice, murine $\beta$ defensins (MBDs) are chemotactic for subsets of murine $\mathrm{T}$ cells and iDCs that express CCR6 ${ }^{32}{ }^{33}$ Furthermore, they also have potent immunoadjuvant activity and promote antitumour adaptive immune responses ${ }^{34}$ to injection of mice with plasmids containing cDNA for selected chemokines or $\beta$ defensins linked to HIV ENV antigen or to a tumour antigen, such as the Fv portion of immunoglobulin expressed by murine B cell lymphomas. Fusion products consisting of chemokines linked to HIV-gpl20 will induce mucosal as well as systemic immunity. ${ }^{34}$ Although the immunoglobulin "self" antigens were not immunogenic when administered by themselves, they induced murine immune responses when administered intracutaneously using a gene gun or as proteins linked to a $\beta$ defensin ligand. As unlinked mixtures of the tumour antigen and $\beta$ defensin or antigen linked to a prodefensin molecule that cannot interact with CCR6 are inactive, it is reasonable to propose that the $\beta$ defensins facilitated the delivery of antigen to receptors on iDCs. The fact that this approach breaks tolerance to self suggests that delivery of antigens to these receptors favours the processing by iDCs and subsequent immunogenic presentation of the antigen by mature dendritic cells. MBD3 linked to the Fv portion of an immunoglobulin from murine lymphomas when injected into mice induces a considerable antibody response, but does not protect mice against a tumour challenge. On the other hand, MBD2 linked to the same Fv antigen induces moderate levels of antibody to the tumour antigen, but considerable cellular immunity, as $50 \%$ of the immunised mice are protected against tumour challenge. ${ }^{32}$ Tumour immunity usually involves the participation of Thl cytokines such as IFN $\gamma$ and the induction of cytotoxic T lymphocytes. This was also true of the MBD2 induced tumour immunity, because immunisation with MBD2 fused to the tumour Fv antigen failed to protect IFN $\gamma$ knockout mice. In contrast, the MBD3 fusion product did not induce IFN $\gamma$. These perplexing differences in the effects of MBD2 and MBD3, which use the same CCR6 receptors, were therefore further investigated.

\section{MBD2 MATURATION OF DENDRITIC CELLS IS TLR4 DEPENDENT}

The possibility that the $\beta$ defensins had activating as well as chemotactic effects on iDCs was evaluated. Incubation of iDCs with MBD2 or LPS, but not MBD3, induced the differentiation into mature cells which expressed CD11c, CD40, and B7.2 cell surface molecules. ${ }^{33}$ These mature dendritic cells became capable of presenting antigen, as evidenced by the fact that they were able to augment a mixed leucocyte (proliferative) response. Furthermore, MBD2, like LPS, induced dendritic cells to produce cytokines, such as IL1, TNF, IL6, and IL12, and chemokines, such as IL8, MDC, IP-10, MIP1- $\alpha$ and to up regulate the expression of the CCR7 receptor (table 4). However, as predicted, maturation of dendritic cells was associated with a decrease in the expression of chemokine receptors such as CCR2, CCR5, and CCR6 and the mannose and scavenger 2 receptors. The possibility that LPS contamination of the recombinant protein accounted for its activating effect on iDCs was ruled out (table 4), as limulus assays failed to detect any LPS in the MBD2 preparation. The activity of MBD2, unlike that of LPS, was destroyed by digestion with proteinase $\mathrm{K}$ and boiling for 15 minutes. In contrast, the activity of LPS, but not of MBD2, was blocked by polymixin B, diphosphoryl lipid A from Rhodobacterium, and by incubating 
Table 4 Comparison of effects on immature dendritic cells (iDCs) of murine BD2 and lipopolysaccharide (LPS)

\begin{tabular}{lll}
\hline & LPS & MBD2 \\
\hline Induces iDC chemokine production - IL8, RANTES, MDC, IP10 and MIP1 $\alpha$ & + & + \\
Induces iDC chemokine receptor - CCR7 & + & + \\
Induces iDC cytokine production - ILI $\alpha, \beta$, TNF, IL6, IL12, IFN & + & + \\
& + & + \\
Suppresses chemokine receptor expression - CCR2, CCR5, CCR6 & + \\
Suppresses receptor expression - mannose and scavenger R2 & + & Yes \\
Blocked by proteinase K and by boiling for 15 min & No & No \\
Blocked by polymixin B and diphosphoryl lipid A & Yes & Yes \\
Activates iDCs in serum-free medium & No & Yes \\
Activates iDCs from CCR6 -/- mice & Yes & No \\
Activates iDCs from TLR4 mutant mice & No & \\
\hline IFN, interferon; IL, interleukin; TLR, toll-like receptor; TNF, tumour necrosis factor. & &
\end{tabular}

iDCs in serum-free medium lacking LBP for one hour. The activating effect of LPS and MBD2 on iDCs from CCR6 knockout mice was also compared. Unexpectedly, the MBD2, as well as LPS, was able to induce maturation of iDCs in the absence of CCR6, suggesting that another receptor interaction may be responsible for this effect. Because of the similarity of the effects of LPS and MBD2, their capacity to stimulate iDCs from mice with mutant TLR4 genes was then compared. iDCs obtained from defective $\mathrm{C} 3 \mathrm{H} / \mathrm{HeJ}$ and $\mathrm{C} 57 \mathrm{BL} 10 \mathrm{ScN}$ cr mice with TLR4 gene defects were unresponsive to both LPS and MBD2. MBD2 also induced receptor gene expression of HEK293 cells transiently cotransfected with murine TLR4 and MD2 genes. These results suggested that MBD2 uses TLR4 to induce Thl immune responses independent of its CCR6 dependent chemotactic effect. Consequently, these data identify MBD2 as a unique endogenous ligand for TLR4 and appear to reflect an additional adaptation by which this defensin molecule is able to activate adaptive immune responses.

\section{ACKNOWLEDGEMENTS}

This project was funded in whole or in part by Federal funds from the National Cancer Institute, under contract No NO1-CO-12400.

\section{Authors' affiliations}

J J Oppenheim, D Yang, Laboratory of Molecular Immunoregulation, Center for Cancer Research, National Cancer Institute, Frederick, MD 21702, USA

A Biragyn, L W Kwak, Experimental Transplantation and Immunology Branch, Center for Cancer Research, National Cancer Institute, USA

The contents of this publication do not necessarily reflect the views or policies of the Department of Health and Human Services, nor does mention of trade names, commercial products, or organisations imply endorsement by the US Government.

The publisher or recipient acknowledges the right of the US Government to retain a non-exclusive, royalty-free license in and to any copyright covering the article.

Correspondence to: Dr J J Oppenheim, Laboratory of Molecular Immunoregulation, Building 560, Room 21-89A, National Cancer Institute, Frederick, Maryland 21702-1201, USA; Oppenhei@ncifcrf.gov

\section{REFERENCES}

1 Hoffmann JA, Kafatos FC, Janeway CA Jr, Ezekowitz RAB. Phylogenetic perspectives in innate immunity. Science 1999:284:1313-18.

2 Medzhitov R, Janeway CA Jr. Innate immunity: the virtues of a nonclonal system of recognition. Cell 1997;91:295-8.

3 Banchereau J, Steinman RM. Dendritic cells and the control of immunity. Nature 1998;392:245-51.

4 Zasloff $M$. Antimicrobial peptides of multicellular organisms. Nature 2002;415:389-95

5 Boman HG. Gene-encoded peptide antibiotics and the concept of innate immunity: an update review. Scand J Immunol 1998;48:15-25.

6 Scott MG, Hancock REW. Cationic antimicrobial peptides and their multifunctional role in the immune system. Crit Rev Immunol 2002;20:407-31
7 Lehrer RI, Ganz T. Antimicrobial peptides in mammalian and insect host defense. Curr Opin Immunol 1999;1 1:23-7.

8 Ganz T, Lehrer RI. Antimicrobial peptides of vertebrates. Curr Opin Immunol 1998:10:41-4.

9 Zhang L, Yu W, He T, Yu J, Caffrey RE, Dalmasso EA, et al. Contribution of human $\alpha$-defensin 1, 2, and 3 to the anti-HIV-1 activity of CD8 antiviral factor. Science 2002;298:995-1000.

10 Rugeles MT, Trubey CM, Bedoya VI, Pinto LA, Oppenheim JJ, Rybak $S M$, et al. Ribonuclease is partly responsible for the HIV-1 inhibitory effect activated by HLA alloantigen recognition. AIDS 2003;17:481-6.

11 Hoover DM, Rajashankar KR, Blumenthal R, Puri A, Oppenheim JJ, Chertov $O$, et al. The structure of human $\beta$-defensin- 2 shows evidence of higher order oligomerization. J Biol Chem 2000;275:32911-18.

12 Hoover DM, Boulegue C, Yang D, Oppenheim JJ, Tucker KD, Lu W, et al. The structure of human MIP-3 $\alpha / C C L 20$ : linking antimicrobial and CCR6 receptor binding activities with human $\beta$-defensins. J Biol Chem 2002;277:37647-54

13 Yang D, Chen Q, Schmidt AP, Anderson GM, Wang J, Wooters JM, et al. LL-37, the neutrophil granule- and epithelial cell-derived cathelicidin, utilizes formyl peptide receptor-like 1 (FPRL1) as a receptor to chemoattract human peripheral blood neutrophils, monocytes, and T cells. J Exp Med 2000;192:1069-74

14 Yang D, Chertov O, Oppenheim JJ. The role of mammalian antimicrobial peptides and proteins in awakening of innate host defenses and adaptive immunity. Cell Mol Life Sci 2001;58:978-89.

15 Agerberth B, Charo J, Werr J, Olsson B, Idali F, Lindbom L, et al. The human antimicrobial and chemotactic peptides LL-37 and $\alpha$-defensins are expressed by specific lymphocyte and monocyte populations. Blood 2000;96:3086-93.

16 Wilson CL, Ouellette AJ, Satchell DP, Ayabe T, Lopez-Boado YS, Stratman JL, et al. Regulation of intestinal $\alpha$-defensin activation by the metalloproteinase matrilysin in innate host defense. Science 1999;286:113-17

17 Bals R, Weiner D, Meegalla R, Accurso F, Wilson J. Salt-independent abnormality of antimicrobial activity in cystic fibrosis airway surface fluid. Am J Respir Cell Mol Biol 2001;25:21-5.

18 Panyutich AV, Panyutich EA, Krapivin VA, Baturevich EA, Ganz T. Plasma defensin concentrations are elevated in patients with septicemia or bacterial meningitis. J Lab Clin Med 1993;122:202-7.

19 Yang D, Biragyn A, Kwak LW, Oppenheim JJ. Mammalian defensins in immunity: more than just microbicidal. Trends Immunol 2002;23:291-6.

20 Schutte BC, Mitros JP, Bartlett JA, Walters JD, Jia HP, Welsh M, et al. Discovery of five conserved beta-defensin gene clusters using a computational search strategy. Proc Natl Acad Sci USA 2002;99:2129-33

21 Moser C, Weiner DJ, Lysenko E, Bals R, Weiser JN, Wilson JM $\beta$-Defensin 1 contributes to pulmonary innate immunity in mice. Infect Immun 2002;70:3068-72.

22 Morrison G, Kilanowski F, Davidson D, Dorin J. Characterization of the mouse $\beta$ defensin 1, Defb 1, mutant mouse model. Infect Immun 2002; 70:3053-60

23 Nizet V, Ohtake T, Lauth X, Trowbridge J, Rudisill J, Dorschner RA. et al. Innate antimicrobial peptide protects the skin from invasive bacterial infection. Nature 2001;414:454-7

24 Chertov O, Michiel DF, Xu L, Wang JM, Tani K, Murphy WJ, et al. Identification of defensin-1, defensin-2, and CAP37/azurocidin as T-cell chemoattractant proteins released from interleukin-8-stimulated neutrophils. J Biol Chem 1996;271:2935-40

25 Yang D, Chertov O, Bykovskaia SN, Chen Q, Buffo M, Shogan J, et al. $\beta$-Defensins: linking innate and adaptive immunity through dendritic and T cell CCR6. Science 1999:286:525-8.

26 Zhu $\mathbf{Q}$, Solomon S. Isolation and mode of action of rabbit corticostatic (antiadrenocorticotropin) peptides. Endocrinology 1992;130:1413-23.

27 Yang D, Chen Q, Chertov O, Oppenheim JJ. Human neutrophil defensins selectively chemoattract naïve T and immature dendritic cells. J Leukoc Biol 2000;68:9-14.

28 Garcia JR, Jaumann F, Schulz S, Krause A, Rodriguez-Jimenez J, Forssmann $U$, et al. Identification of a novel, multifunctional $\beta$-defensin 
(human $\beta$-defensin 3 ) with specific antimicrobial activity: its interaction with plasma membranes of Xenopus oocytes and the induction of macrophage chemoattraction. Cell Tissue Res 2001;306:257-64.

29 Niyonsaba F, Someya A, Hirata M, Ogawa H, Nagaoka I. Evaluation of the effects of peptide antibiotics human $\beta$-defensin-1/2 and LL-37 on histamine release and prostaglandin $D_{2}$ production from mast cells. Eur J Immunol 2001;31:1066-75.

30 Lillard JW Jr, Boyaka PN, Chertov O, Oppenheim JJ, McGhee JR. Mechanisms for induction of acquired host immunity by neutrophil peptide defensins. Proc Natl Acad Sci USA 1999:96:651-6.

31 Tani K, Murphy WJ, Chertov O, Salcedo R, Koh CY, Utsunomiya I, et al. Defensins act as potent adjuvants that promote cellular and humoral immune responses in mice to a lymphoma idiotype and carrier antigens. Int Immunol 2000; 12:691-700.

32 Biragyn A, Surenhu M, Yang D, Ruffini PA, Haines BA, Klyushnenkova $E$, et al. Mediators of innate immunity that target immature, but not mature, dendritic cells induce antitumor immunity when genetically fused with nonimmunogenic tumor antigens. J Immunol 2001;167:6644-53.

33 Biragyn A, Ruffini PA, Leifer CA, Klyushnenkova E, Shakhov A, Chertov $\mathrm{O}$, et al. Toll-like receptor 4-dependent activation of dendritic cells by $\beta$-defensin 2. Science 2002;298:1025-9.

34 Biragyn A, Belyakov IM, Chow YH, Dimitrov DS, Berzofsky JA, Kwak LW. DNA vaccines encoding human immunodeficiency virus-1 glycoprotein 120 fusions with proinflammatory chemoattractants induce systemic and mucosal immune responses. Blood 2002;100:1153-9.
35 Scott MG, Vreugdenhil AC, Buurman WA, Hancock REW. Cutting edge: cationic antimicrobial peptides block the binding of lipopolysaccharide cationic antimicrobial peptides block the binding of lipopolys
(LPS) to LPS binding protein. J Immunol 2000; 164:549-53.

36 Duits LA, Ravensbergen B, Rademaker M, Hiemstra PS, Nibbering PH. Expression of $\beta$-defensin 1 and 2 mRNA by human monocytes, macrophages and dendritic cells. Immunology 2002;106:517-25.

37 Niyonsaba F, Iwabuchi K, Matsuda H, Ogawa H, Nagaoka I. Epithelial cell-derived human beta-defensin-2 acts as a chemotaxin for mast cells cell-derived human beta-defensin-2 acts as a chemotaxin for mast cells
through a pertussis toxin-sensitive and phospholipase C-dependent pathway. Int Immunol 2002;14:421-6

38 Niyonsaba F, Iwabuchi K, Someya A, Hirata M, Matsuda H, Ogawa H, et al. A cathelicidin family of human antibacterial peptide LL-37 induces mast cell chemotaxis. Immunology 2002; 106:20-6.

39 Zhang G, Wu H, Shi J, Ganz T, Ross CR, Blecha F. Molecular cloning and tissue expression of porcine $\beta$-defensin-1. FEBS Lett 1998:424:37-40.

40 Verbanac $D$, Zanetti $M$, Romeo D. Chemotactic and protease-inhibiting activities of antibiotic peptide precursors. FEBS Lett 1993;371:255-8.

41 Territo MC, Ganz T, Selsted ME, Lehrer R. Monocyte-chemotactic activity of defensins from human neutrophils. J Clin Invest 1989;84:2017-20.

42 Huang HJ, Ross CR, Blecha F. Chemoattractant properties of PR-39, a neutrophil antibacterial peptide. J Leukoc Biol 1997;61:624-9.

43 Cella M, Sallusto F, Lanzavecchia A. Origin, maturation and antigen presenting function of dendritic cells. Curr Opin Immunol 1997;9:10-16.

44 Liu YJ. Dendritic cell subsets and lineages, and their functions in innate and adaptive immunity. Cell 2001;106:259-62. [AQ:2] 